\title{
Ventilation rate in office buildings and sick building syndrome
}

\author{
Jouni JK Jaakkola, Pauli Miettinen
}

\begin{abstract}
Objective-To examine the relation between ventilation rate and occurrence of symptoms of the eyes, nose, throat, and skin as well as general symptoms such as lethargy and headache, often termed the sick building syndrome. Methods-A cross sectional population based study was carried out in 399 workers from 14 mechanically ventilated office buildings without air recirculation or humidification, selected randomly from the Helsinki metropolitan area. The ventilation type and other characteristics of these buildings were recorded on a site visit and the ventilation in the rooms was assessed by measuring the airflow through the exhaust air outlets in the room. A questionnaire directed at workers inquired about the symptoms and perceived air quality and their possible personal and environmental determinants (response rate $81 \%$ ). The outcomes were weekly work related symptoms experienced during the previous 12 months and symptom groups defined either by their anatomical location or hypothesised mechanism.
\end{abstract}

Results-In logistic regression analysis, the adjusted odds ratio (OR) for any symptom of interest was $3.03(95 \%$ confidence interval $(95 \% \mathrm{CI}) 1 \cdot 13$ to $8 \cdot 10)$ in the very low ventilaton category of below $51 / \mathrm{s}$ per person and $2.24(0.89$ to 5.65$)$ in the high ventilation category of over $25 \mathrm{l} / \mathrm{s}$ per person compared with the reference $(15-<251 / s)$. The ORs for ocular $(1 \cdot 27$, $1 \cdot 11$ to $1 \cdot 46)$, nasal $(1 \cdot 17,1 \cdot 06$ to $1 \cdot 29)$, skin symptoms $(1.18,1.05$ to 1.32$)$, and lethargy $(1.09,1.00$ to 1.19$)$ increased significantly by a unit decrease in ventilation from 25 to $01 / \mathrm{s}$ per person.

Conclusion-The results suggest that outdoor air ventilation rates below the optimal (15 to $25 \mathrm{l} / \mathrm{s}$ per person) increase the risk of the symptoms of sick building syndrome with the sources of pollutants present in mechanically ventilated office buildings. The Finnish guideline value is $10 \mathrm{l} / \mathrm{s}$ per person.

(Occup Environ Med 1995;52:709-714)

Keywords: building ventilation; air pollution, indoor; sick building syndrome

Office workers commonly report the indoor air quality to be unacceptable and experience non-specific symptoms of the eyes, nose, throat, and skin as well as general symptoms such as lethargy and headache. ${ }^{1-8}$ The similarity of the symptom pattern in different study populations and their causal attribution to the building environment has given rise to the concept of the sick building syndrome. ${ }^{9}$

Air change plays a central role in lowering the levels of indoor air pollutants emitted from the indoor environment or produced by the occupants or their activities such as smoking, photocopying, or handling paper. It is commonly accepted that ventilation is necessary for the wellbeing of the occupants. The role of ventilation is complicated by the observations that workers in air conditioned buildings experience more symptoms than workers in naturally ventilated buildings. ${ }^{6710-13}$ Mechanical ventilation-that is, mechanical supply and exhaust of air-has also been related to these symptoms in some studies, ${ }^{6710-11}$ but not in others. ${ }^{13} 14$ Six earlier studies, five experimental $^{15-19}$ and one observational ${ }^{1420}$ have assessed the relation between ventilation rate and occurrence of symptoms. The results are inconsistent, although the weight of evidence has been interpreted to suggest that ventilation rates below $10 \mathrm{l} / \mathrm{s}$ per person would increase the risk of symptoms of sick building syndrome. ${ }^{21}$ These results do not provide sufficient information to determine the optimum outdoor ventilation rate needed in the existing buildings to protect the occupants from adverse health effects.

We examined the relation between ventilation rate and occurrence of symptoms of the sick building syndrome in office workers in a population based cross sectional study carried out in a Helsinki metropolitan area.

\section{Methods}

BUILDINGS AND STUDY POPULATION

A random sample of 50 office buildings with at least 10 workers in each was selected from the Helsinki Metropolitan Area Building Registry, which included all the 894 office buildings in the defined geographical region. ${ }^{10}$ The owners of nine buildings were not willing to participate in the study. The remaining 41 buildings and their occupants were included in the study, and a person registry was made of all the workers. In six buildings a few firms, comprising only a small proportion of the workers, did not participate. A self administered questionnaire was posted to 3317 workers. A total of 2678 workers completed the questionnaire (response rate $81 \%$ ), 605 subjects did not participate, and 34 returned an incomplete form. 
Table 1 Characteristics of the study population

\begin{tabular}{|c|c|c|c|c|c|}
\hline \multirow[b]{2}{*}{ Characteristic } & \multicolumn{5}{|c|}{ Ventilation category ( $/$ s per person) } \\
\hline & $\begin{array}{l}\text { Very low } \\
(<5) \\
n=53 \\
(\%)\end{array}$ & $\begin{array}{l}\text { Low } \\
(5-<15) \\
n=171 \\
(\%)\end{array}$ & $\begin{array}{l}\text { Medium } \\
(15-<25) \\
n=123 \\
(\%)\end{array}$ & $\begin{array}{l}\text { High } \\
(\geqslant 25) \\
n=52 \\
(\%)\end{array}$ & $\begin{array}{l}\text { Total } \\
n=399 \\
(\%)\end{array}$ \\
\hline \multicolumn{6}{|l|}{ Personal characteristics } \\
\hline \multicolumn{6}{|l|}{$\begin{array}{l}\text { Sex: } \\
\text { Female }\end{array}$} \\
\hline $\begin{array}{l}\text { Female } \\
\text { Age: }\end{array}$ & $73 \cdot 6$ & $56 \cdot 1$ & $43 \cdot 9$ & $51 \cdot 9$ & $54 \cdot 1$ \\
\hline \multicolumn{6}{|l|}{ Age: } \\
\hline $\begin{array}{l}\leqslant 24 \\
25-34\end{array}$ & $3 \cdot 8$ & $11 \cdot 7$ & $4 \cdot 9$ & $11 \cdot 5$ & $8 \cdot 5$ \\
\hline $25-34$ & $28 \cdot 3$ & $36 \cdot 3$ & $28 \cdot 5$ & $17 \cdot 3$ & $30 \cdot 3$ \\
\hline $35-44$ & $35 \cdot 9$ & $28 \cdot 7$ & $31 \cdot 7$ & $34 \cdot 6$ & $31 \cdot 3$ \\
\hline $45-54$ & $15 \cdot 1$ & $20 \cdot 5$ & $26 \cdot 8$ & $32 \cdot 7$ & $23 \cdot 3$ \\
\hline$\geqslant 55$ & $17 \cdot 0$ & $2 \cdot 9$ & $8 \cdot 1$ & 3.9 & $6 \cdot 5$ \\
\hline \multicolumn{6}{|l|}{ Professional education: } \\
\hline University or college & $60 \cdot 4$ & $64 \cdot 9$ & $80 \cdot 5$ & $66 \cdot 0$ & $69 \cdot 4$ \\
\hline Vocational school & $16 \cdot 7$ & $11 \cdot 3$ & $8 \cdot 1$ & $18 \cdot 0$ & $11 \cdot 8$ \\
\hline No & $14 \cdot 6$ & $16 \cdot 1$ & $5 \cdot 7$ & $8 \cdot 0$ & $11 \cdot 3$ \\
\hline Other & $8 \cdot 3$ & $7 \cdot 7$ & $5 \cdot 7$ & $8 \cdot 0$ & $7 \cdot 0$ \\
\hline Atopy & $45 \cdot 3$ & $29 \cdot 8$ & $37 \cdot 4$ & $32 \cdot 7$ & $34 \cdot 6$ \\
\hline \multicolumn{6}{|l|}{ Smoking } \\
\hline Current & $30 \cdot 2$ & $32 \cdot 2$ & $34 \cdot 2$ & $32 \cdot 7$ & $32 \cdot 6$ \\
\hline Former & $20 \cdot 8$ & $18 \cdot 7$ & $21 \cdot 1$ & $19 \cdot 2$ & $19 \cdot 8$ \\
\hline \multicolumn{6}{|l|}{ Office environment, work: } \\
\hline Shared office & $64 \cdot 2$ & $64 \cdot 3$ & $38 \cdot 2$ & $32 \cdot 7$ & $52 \cdot 1$ \\
\hline Passive smoking & $5 \cdot 7$ & $0 \cdot 6$ & $1 \cdot 6$ & $\begin{array}{r}0 \cdot 0 \\
027\end{array}$ & $1 \cdot 5$ \\
\hline Textile wall materials & $11 \cdot 3$ & $13 \cdot 5$ & $8 \cdot 2$ & $32 \cdot 7$ & $14 \cdot 0$ \\
\hline Wall to wall carpets & 1.9 & 5.9 & $17 \cdot 9$ & $19 \cdot 2$ & $10 \cdot 8$ \\
\hline Sealed windows & $15 \cdot 1$ & $9 \cdot 4$ & $9 \cdot 8$ & $15 \cdot 4$ & $11 \cdot 0$ \\
\hline $\begin{array}{l}\text { Handling of } \\
\text { self copying paper }\end{array}$ & $24 \cdot 5$ & $26 \cdot 9$ & $29 \cdot 3$ & $30 \cdot 8$ & $27 \cdot 8$ \\
\hline VDT use (h/week, & $19 \cdot 1$ & $19 \cdot 4$ & $18 \cdot 8$ & $16 \cdot 2$ & $18 \cdot 8$ \\
\hline mean (SD)) & $(12 \cdot 4)$ & $(11 \cdot 9)$ & $(12 \cdot 2)$ & $(9 \cdot 5)$ & $(11 \cdot 8)$ \\
\hline Photocopying (h/week, & 1.7 & $2 \cdot 2$ & 1.8 & $2 \cdot 6$ & $2 \cdot 1$ \\
\hline $\begin{array}{l}\text { mean (SD)) } \\
\text { Psychosocial environment: }\end{array}$ & $(1 \cdot 8)$ & $(6 \cdot 0)$ & $(2 \cdot 2)$ & $(6 \cdot 1)$ & $(4 \cdot 7)$ \\
\hline \multicolumn{6}{|l|}{$\begin{array}{l}\text { Psychosocial environment: } \\
\text { Atmosphere: }\end{array}$} \\
\hline Satisfied or neutral & $86 \cdot 5$ & $87 \cdot 1$ & $84 \cdot 6$ & $88 \cdot 5$ & $86 \cdot 2$ \\
\hline Unsatisfied & $11 \cdot 5$ & $9 \cdot 4$ & $14 \cdot 6$ & $7 \cdot 8$ & $11 \cdot \overline{1}$ \\
\hline Very unsatisfied & 1.9 & $3 \cdot 5$ & 0.8 & 3.9 & $2 \cdot 5$ \\
\hline \multicolumn{6}{|l|}{ Stress: } \\
\hline Slight, not at all & $45 \cdot 3$ & $43 \cdot 3$ & $45 \cdot 5$ & $38 \cdot 5$ & $43 \cdot 6$ \\
\hline Moderate & $32 \cdot 1$ & $36 \cdot 8$ & $39 \cdot 0$ & $48 \cdot 1$ & $38 \cdot 5$ \\
\hline Much, very much & $22 \cdot 6$ & $19 \cdot 9$ & $15 \cdot 5$ & $13 \cdot 5$ & $18 \cdot 0$ \\
\hline \multicolumn{6}{|l|}{ Interest in work: } \\
\hline Often, almost always & $67 \cdot 9$ & $67 \cdot 2$ & $70 \cdot 7$ & $78 \cdot 8$ & 69.9 \\
\hline Sometimes & $26 \cdot 4$ & $25 \cdot 7$ & $24 \cdot 4$ & $19 \cdot 2$ & $24 \cdot 6$ \\
\hline Rarely, never & $5 \cdot 7$ & $7 \cdot 0$ & 4.9 & 1.9 & $5 \cdot 5$ \\
\hline
\end{tabular}

The present study focused on the mechanically ventilated buildings (both supply and exhaust) that were operated without air recirculation or humidification. A total of 14 buildings, were included; 10 buildings were fitted with simple mechanical ventilation and four were air conditioned. Simple mechanical ventilation refers to buildings with ducted supply and exhaust airflow, but no integrated heating or cooling of air. Partial heating of incoming air is included in this category. Buildings with air conditioning but without humidification are buildings with integrated heating and cooling of incoming air. The study population (table 1) consisted of 399 subjects, 183 men $(45 \cdot 9 \%)$ and 216 women $(54 \cdot 1 \%)$.

\section{OUTCOME CRITERIA}

The outcomes were nine particular symptoms compatible with those described in the sick building syndrome, ${ }^{9}$ including: eye symptoms; nasal dryness, itching or irritation; nasal congestion (stuffy, blocked nose); nasal excretion (runny nose); pharyngeal symptoms; skin symptoms; headache; lethargy; and difficulty in concentrating. Apart from particular symptoms, summary outcomes were also considered, based on either the anatomical location of the symptoms (ocular, nasal, pharyngeal, cutaneous, or general) or on the hypothesised mechanism (mucosal irritation or allergic reaction).
The outcomes were specified as appearing at least weekly, being work related, and the reference time period was the previous year. The questions used are described in detail elsewhere. ${ }^{10}$ These weekly work related symptoms were used in forming the summary outcomes. The presence of one or more symptoms in the corresponding symptom group indicated a positive response. Mucosal irritation was based on reported dryness, itching or irritation of eyes; nasal dryness; nasal congestion; or pharyngeal irritation. Allergic reaction was based on reported dryness, itching, or irritation of eyes; nasal congestion; nasal excretion or pharyngeal irritation.

\section{DATA COLLECTION}

A self administered questionnaire asked about the symptoms typical of the sick building syndrome and perceptions of odour and thermal comfort. Personal factors, information on health, smoking, and work environment were also asked for in the questionnaire. The questionnaire was distributed by post and requested twice from the non-responders.

Basic information on the building, including the size and type of building, was available in the Building Registry. Further information was collected in an interview with the landlords and custodians of the buildings and on site visits.

The air change in the rooms was assessed from November 1991 to February 1992 by measuring the airflow through the exhaust air outlets in the room. An anemometer tube connected to a hot wire anemometer was used in the measurements. The anemometer was regularly calibrated in the laboratory, no drift in the calibration of the anemometer was discovered during the study. This method gives a good estimate of the total air change in a room, as all mechanically ventilated office buildings in Finland are designed to have negative pressure. The floor area and volume of the rooms were measured at the same time as the ventilation measurements. From these figures, the ventilation rates per person in each room were calculated.

\section{STATISTICAL METHODS}

The age (five categories) and sex standardised prevalences of weekly, work-related symptoms were estimated in four different ventilation categories: very low ( $<5 \mathrm{l} / \mathrm{s}$ per person), low $(5-<15)$, medium $(15-<25)$ and high $(>251 / \mathrm{s}$ per person). The relation between the level of airflow and occurrence of symptoms was then assessed in logistic regression analysis. ${ }^{22}{ }^{23}$ Adjusted odds ratios (ORs) were computed for the very low, low, and high ventilation categories by the indicator technique with the medium ventilation category as a control, because of the lowest prevalences. ${ }^{22}$ The following covariates were included in the models: age, sex, professional education, atopy (any history of eczema, allergic rhinitis, conjunctivitis, or asthma), personal smoking, type of ventilation (mechanical or air conditioned), number of workers in the room, passive smoking, textile wall materials, wall to wall carpets, 
Table 2 Age and sex standardised prevalences (\%) of weekly, work related symptoms during previous 12 months in different ventilation categories

\begin{tabular}{|c|c|c|c|c|c|}
\hline & \multicolumn{5}{|c|}{ Ventilation category ( $/ /$ s per person) } \\
\hline & $\begin{array}{l}\text { Very low } \\
(<5)\end{array}$ & $\begin{array}{l}\text { Low } \\
(5-<15)\end{array}$ & $\begin{array}{l}\text { Medium } \\
(15-<25)\end{array}$ & $\begin{array}{l}\text { High } \\
(\geqslant 25)\end{array}$ & Total \\
\hline & $\begin{array}{l}n=53 \\
(\%)\end{array}$ & $\begin{array}{l}n=171 \\
(\%)\end{array}$ & $\begin{array}{l}n=123 \\
(\%)\end{array}$ & $\begin{array}{l}n=52 \\
(\%)\end{array}$ & $\begin{array}{l}n=399 \\
(\%)\end{array}$ \\
\hline $\begin{array}{l}\text { Eye symptoms } \\
\text { Nasal irritation } \\
\text { Nasal congestion } \\
\text { Nasal discharge } \\
\text { Pharyngeal symptoms } \\
\text { Skin symptoms } \\
\text { Headache } \\
\text { Lethargy } \\
\text { Difficulty concentrating }\end{array}$ & $\begin{array}{r}15 \cdot 8 \\
11 \cdot 2 \\
14 \cdot 3 \\
13 \cdot 1 \\
8 \cdot 4 \\
13 \cdot 0 \\
5 \cdot 3 \\
14 \cdot 6 \\
4 \cdot 6\end{array}$ & $\begin{array}{r}5 \cdot 7 \\
12 \cdot 8 \\
4 \cdot 5 \\
3 \cdot 9 \\
7 \cdot 4 \\
5 \cdot 1 \\
6 \cdot 3 \\
12 \cdot 6 \\
8 \cdot 1\end{array}$ & $\begin{array}{r}4 \cdot 3 \\
5 \cdot 0 \\
2 \cdot 2 \\
1 \cdot 7 \\
0 \cdot 0 \\
0 \cdot 9 \\
3 \cdot 4 \\
10 \cdot 4 \\
5 \cdot 9\end{array}$ & $\begin{array}{r}17 \cdot 6 \\
7 \cdot 7 \\
9 \cdot 6 \\
5 \cdot 7 \\
7 \cdot 7 \\
9 \cdot 7 \\
6 \cdot 8 \\
13 \cdot 5 \\
10 \cdot 8\end{array}$ & $\begin{array}{r}8 \cdot 5 \\
10 \cdot 0 \\
6 \cdot 0 \\
5 \cdot 3 \\
4 \cdot 5 \\
5 \cdot 0 \\
5 \cdot 0 \\
11 \cdot 5 \\
6 \cdot 3\end{array}$ \\
\hline
\end{tabular}

sealed windows, work with a video display unit, handling of self copying paper, photocopying, satisfaction with psychosocial atmosphere, work stress, interesting work, average weekly time in the office, and duration of employment in the building. Finally, parametric models were fitted, when applicable, to examine the form of the relation between ln odds of the outcome and ventilation rate. For some outcomes a linear relation was found between ln odds and ventilation rate in the range of 0 to $25 \mathrm{l} / \mathrm{s}$ per person. This corresponds to an exponential relation between the risk of symptoms and ventilation rate in this range. When there were problems with convergence of the full model, a forward stepwise modelling approach was applied with ventilation rate, sex, and age forced into the model and other variates selected according to the improvement of fit $(0.25$ significance level as the criterion for entry and exclusion). ${ }^{23}$

\section{Results}

STUDY POPULATION

The distributions of the potential confounders varied to some extent among the ventilation categories (table 1). The proportion of women was considerably greater in the very low $(73.5 \%)$ and low ventilation categories $(56.1 \%)$ than in the medium $(43.9 \%)$ and high ventilation categories (51.9\%), and the age distribution varied among the ventilation categories. Atopy, shared office, passive smoking, sealed windows, and work stress were more common in the low ventilation categories, whereas textile wall materials, wall to wall carpets, and handling of self copying paper were most common in the high ventilation category.

\section{VENTILATION RATE AND SYMPTOMS}

The median ventilation rate in the rooms was $13.8 \mathrm{l} / \mathrm{s}$ per person, $10.6 \mathrm{l} / \mathrm{s}$ per person for buildings with simple mechanical ventilation and $16.5 \mathrm{l} / \mathrm{s}$ per person for air conditioned buildings. The proportion of subjects who occupied offices with the ventilation rate below $5 \mathrm{l} / \mathrm{s}$ per person was $13 \%$, and $56 \%$ of the subjects were in roons with the ventilation rate below $15 \mathrm{l} / \mathrm{s}$ per person.

The age and sex standardised prevalences of weekly work related symptoms were the lowest in the medium ventilation category for all the symptoms except for difficulty in concentrating (table 2). Ocular, nasal, pharyngeal and skin symptoms and lethargy showed an increasing trend from the medium to very low ventilation category. The prevalences of symptoms in the high ventilation category were also considerably greater than in the medium ventilation category.

The adjusted risk estimates provided similar evidence of the relation between ventilation rate and risk of symptoms (table 3 ). The risk estimates in the lowest ventilation category were highest for skin (OR 41.0), nasal $(7 \cdot 7)$, and eye symptoms $(5 \cdot 6)$, but also considerably increased for general symptoms $(2 \cdot 1)$ when compared with the medium ventilation category. All except general symptoms were significant. The corresponding risk estimates in the high ventilation category were also all raised, ranging from $1 \cdot 1$ to $14 \cdot 8$, significant for eye symptoms. The adjusted ORs for mucosal irritation (OR $4.21,95 \%$ confidence interval (95\% CI) 1.35 to 13.13$)$ and allergic reaction $(7.04,2.02$ to 24.54$)$ were significantly increased.

Table 3 Adjusted ORs of weekly, work related symptoms during previous 12 months in very low, low, and high ventilation categories compared the with medium ventilation category ( $n=399$; ventilation rates are in $\mathrm{l} / \mathrm{s}$ per person)

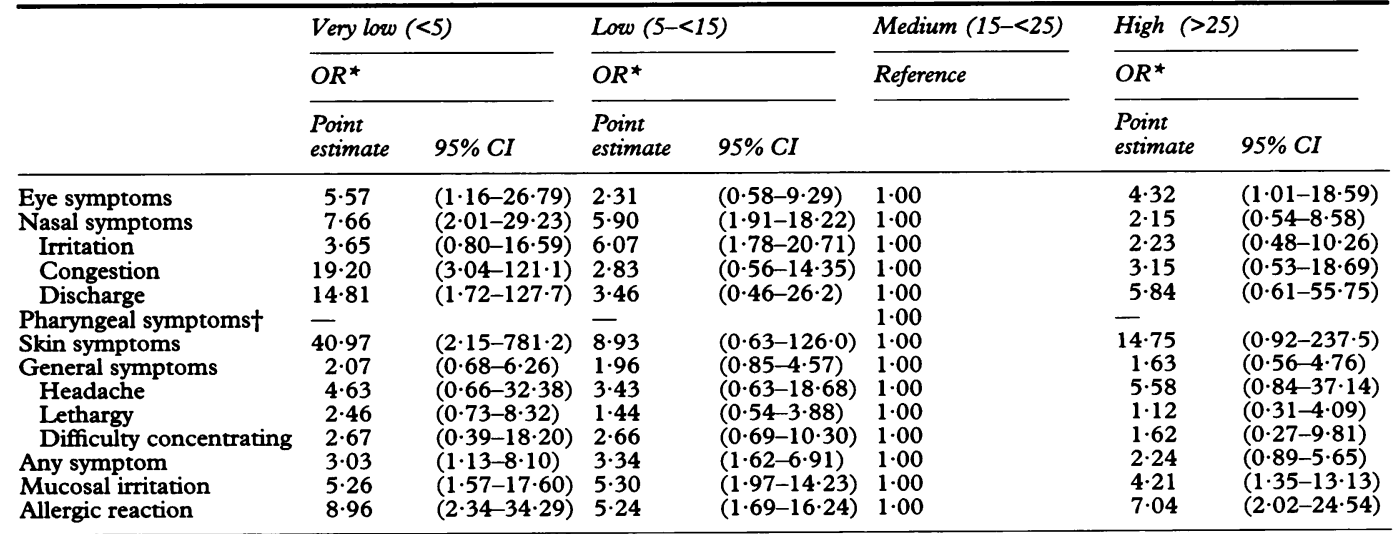

*Adjustment was made in the logistic regression for age, sex, professional education, atopy (any history of eczema, allergic rhinitis conjunctivitis, or asthma), number of workers in the room, personal and passive smoking, type of ventilation, textile wall materials, wall to wall carpets, sealed windows, work with a video display unit, handling of self copying paper, photocopying and satisfaction with psychosocial atmosphere, job stress, interesting job, average weekly time in the office, and duration of employment in the building.

†No subjects with symptoms in the control group. 
Table 4 Increase in ORs of weekly, work related symptoms during the previous 12 months per $1 \mathrm{l} / \mathrm{s}$ decrease in ventilation rate between 25 to $0 \mathrm{l} / \mathrm{s}$ per person $(n=347)$

\begin{tabular}{|c|c|c|}
\hline & \multicolumn{2}{|l|}{$O R^{*}$} \\
\hline & Point estimate & $95 \% C I$ \\
\hline Eye symptoms & $1 \cdot 27$ & $1 \cdot 11-1.46 \dagger$ \\
\hline Nasal symptoms & $1 \cdot 17$ & $1.06-1 \cdot 29$ \\
\hline Irritation & $1 \cdot 10$ & $1 \cdot 00-1 \cdot 22$ \\
\hline Congestion & $1 \cdot 30$ & $1 \cdot 13-1 \cdot 50 \dagger$ \\
\hline Discharge & $1 \cdot 17$ & $1.05-1.32 \dagger$ \\
\hline Pharyngeal symptoms & $1 \cdot 12$ & $0.98-1 \cdot 27^{\circ}$ \\
\hline Skin symptoms & $1 \cdot 18$ & $1 \cdot 05-1 \cdot 32 \dagger$ \\
\hline General symptoms & 1.05 & $0 \cdot 97-1 \cdot 14$ \\
\hline Headache & $1 \cdot 01$ & $0 \cdot 89-1 \cdot 15$ \\
\hline Lethargy & 1.09 & $1 \cdot 00-1 \cdot 19$ \\
\hline Difficulty concentrating & 1.02 & $0 \cdot 90-1 \cdot 15$ \\
\hline Any symptom & 1.09 & $1 \cdot 02-1 \cdot 17$ \\
\hline Mucosal irritation & $1 \cdot 15$ & $1 \cdot 05-1 \cdot 25$ \\
\hline Allergic reaction & $1 \cdot 18$ & $1 \cdot 07-1 \cdot 31$ \\
\hline
\end{tabular}

†Stepwise modelling with age and sex forced into the model.

Logistic regression models indicated a significant linear increase in the ln odds of eye, nasal, and skin symptoms and lethargy by a unit decrease in the ventilation rate from $25 \mathrm{l} / \mathrm{s}$ towards 0 (table 4 ). The risk estimates are expressed as a change in OR per $1 \mathrm{l} / \mathrm{s}$ decrease in the ventilation rate.

\section{Discussion}

In the present population based study, the risk of work related symptoms, typical of the sick building syndrome, was found to be related to low outdoor air ventilation rate in the office. Ocular, nasal, pharyngeal, and skin symptoms, as well as lethargy were considerably more common in the rooms with the ventilation rate below $5 \mathrm{l} / \mathrm{s}$ per person compared with the rooms where the rate was considered to be optimal, from 15 to $25 \mathrm{l} / \mathrm{s}$ per person. The risk of these symptoms was estimated to increase exponentially by a unit decrease below the optimal ventilation rate. The risk of symptoms was also increased in the rooms with the ventilation rate above the optimum.

\section{RELATION BETWEEN VENTILATION RATE AND}

\section{SICK BUILDING SYNDROME}

The relation between the ventilation rate and the occurrence of symptoms is complicated, because it depends on several phenomena. Exposure to several chemical and biological indoor air pollutants can have adverse health effects. Air change is essential in lowering the air pollution levels and thus ventilation rates that are too low can be related to adverse health effects when exposure to these pollutants is increased. High ventilation rates could also be related to adverse health effects in two ways. Firstly, outdoor air and the ventilation system are sources of indoor air pollution to the extent that an increase in ventilation rate increases the exposure. Secondly, mechanical ventilation changes the physical properties of indoor air. Berglund and Lindvall suggested that the human sensory system uses a pattern recognition mechanism in the sensing of indoor air with complex environmental adaptation to the inhaled air. ${ }^{24}$ Use of high ventilation rates can lead to extreme homogenisation of air, causing sensory confusion and strain on the system when it is trying to interpret the signals. A possible hypothesis is that sensory symptoms tied to sick buildings of the irritant type ${ }^{24}$ might be related to the homogenisation of air.

\section{VALIDITY OF RESULTS}

The potential sources of systematic error in the assessment of the relation between air change and occurrence of symptoms include selection bias, information bias, and confounding. There are two possible ways that selection bias could have been introduced on an individual level. On the one hand, individual workers with work related dissatisfaction and symptoms could have left work. Presuming that either low or high air change is a determinant of the symptoms, this type of selection would lead to underestimation of the relation between the air change and occurrence of symptoms. On the other hand, the risk estimates could have been overestimated, for example if workers experiencing symptoms and perceptions were more likely to complete the questionnaire and the response rate was related to low ventilation rate. This type of selection was not likely, because the response rate was high $(81 \%)$. An excess of symptoms in the high ventilation category compared with the medium ventilation category could be explained by a selective adjustment to increase the ventilation rate as a response to occupant complaints. The time sequence between exposure and outcome can not be assessed in a cross sectional design, and thus the results should be interpreted cautiously.

The participants were informed about the general objective of studying the environmental determinants of health and well being in office buildings, but no special attention was paid to the role of ventilation. Further, the participants did not know the magnitude of ventilation rate in their room. Thus, information bias is an unlikely explanation of the results.

The results, which indicated that the prevalence of symptoms is related to the magnitude of ventilation rate, could be explained by uneven distributions of other determinants of the outcomes. Most of the known confounders were taken into account in the multivariate analysis. Other unknown confounders not considered in the analysis could theoretically explain our results, but these would have to be both strong determinants of the outcomes and be associated strongly with the ventilation rate.

Some random error was likely both in the measurement of ventilation rates and outcomes. The airflows were measured about a year after participating in the survey. The rooms, where renovation or adjustment of ventilation had taken place after the questionnaire, were excluded from the study. Some changes may have taken place in the buildings without our knowledge. The non-differential misclassification of both the ventilation rate and the outcomes would have led to underestimation of their relation. 
SYNTHESIS WITH PREVIOUS KNOWLEDGE

Three earlier studies that assessed the relation between ventilation rate and occurrence of symptoms ${ }^{14151820}$ reported a significant association between low ventilation rates and the occurrence of symptoms, and three studies ${ }^{161719}$ did not.

Of the five experimental studies, only two found an association between ventilation rate and symptoms. These studies provided strong designs for causal inference in the particular buildings selected. A major limitation from the public health point of view was that the studies were only carried out in between one and four buildings and thus the results can not be used to evaluate the relation in the existing buildings given the current sources of indoor air pollution. In the Finnish controlled parallel group trial the average symptom score for sick building syndrome increased when the outdoor ventilation rate was reduced from an average of $26 \mathrm{l} / \mathrm{s}$ per person to below $7.5 \mathrm{l} / \mathrm{s}$ per person. ${ }^{15}$ In the American two part uncontrolled trial, ${ }^{18}$ building occupants experienced more symptoms at lower than at higher outdoor ventilation rates. The contrasts were $7 \cdot 8$ $1 / \mathrm{s}$ and $17.9 \mathrm{l} / \mathrm{s}$ per person during the summer and $5.8 \mathrm{l} / \mathrm{s}$ and $14.9 \mathrm{l} / \mathrm{s}$ per person during the winter. In the Swedish controlled trial, ${ }^{17}$ the ventilation rate was altered between an average $12 \mathrm{l} / \mathrm{s}$ and $23 \mathrm{l} / \mathrm{s}$ per person, but the alteration had no effect on the symptoms or signs, such as blink rates of the eyes, tear film stability, and visible signs of the eyes, lips, or skin. In the Finnish four period crossover trial ${ }^{19}$ no difference was found in the occurrence of symptoms between the average outdoor ventilation rates of $6 \mathrm{l} / \mathrm{s}$ and $20 \mathrm{l} / \mathrm{s}$ per person. Nor did the similar Canadian six period crossover trial $^{16}$ report any difference in the occurrence of symptoms between the two compared levels of airflows, $14 \mathrm{l} / \mathrm{s}$ and $30 \mathrm{l} / \mathrm{s}$ per person.

The limitations of non-experimental studies, whether cross sectional or casecontrol studies, include the problems of bias and confounding, but a strength from the public health point of view is the feasibility of studying several buildings with population based sampling. This was applied both in the present cross sectional study and in the northern Swedish office illness project with a cross sectional ${ }^{14}$ and case-control study. ${ }^{20}$ In agreement with the present study, the Swedish study reported an increased risk of symptoms in the low ventilation category, below $8.5 \mathrm{l} / \mathrm{s}$ per person (OR $1.87,95 \%$ CI 1.02 to 3.4 ) and in the medium ventilation category from 8.5 to $13.6 \mathrm{l} / \mathrm{s}$ per person $(1.50,0.84$ to 2.7$)$, compared with the control category of $13.6 \mathrm{l} / \mathrm{s}$ per person.

The range of outdoor air ventilation rate considered in the studies is an important issue. Based on his review of the six earlier studies, Mendell suggested that ventilation rates at or below $10 \mathrm{l} / \mathrm{s}$ per person were consistently associated with an increased risk of symptoms, ${ }^{21}$ with the Finnish crossover trial ${ }^{19}$ as an exception. The present study is consistent with this suggestion for the role of low ventilation rates. It should be emphasised that as well as the strength of elimination, the strength of emissions also determines the level of exposure and consequent health effects. The results of the present study suggest that in office buildings with current sources of pollution, the risk of symptoms is already increased when outdoor air ventilation rates are below $15 \mathrm{l} / \mathrm{s}$ per person.

\section{CONCLUDING REMARKS}

The amount of ventilation needed in a given space depends essentially on the sources of pollution in the indoor environment. Under the most simple conditions, the subject him or herself is the only source of air pollution. In modern office environments, pollution sources also include the usual human activities such as smoking, handling of paper, photocopying, and physical objects such as wall and floor surfaces, furniture, and textiles. The situation is even more complicated when the air is recirculated or the supply air is polluted.

Ideally, the interior materials should not emit pollutants. The activities worsening the air quality, such as smoking and photocopying, should take place in separate rooms, and cleaning should be frequent enough to reduce the amount of accumulating particles on the surfaces. Although increasing the air change should be a secondary precaution, the minimum ventilation requirements should be adjusted to the existing conditions in the office environment. The present study was population based and thus provides information on the ventilation requirements in the existing Finnish buildings. It seems that an outdoor air ventilation rate below $5 \mathrm{l} / \mathrm{s}$ per person is a strong determinant of ocular, nasal, pharyngeal, and skin symptoms, as well as general symptoms, and ventilation rates up to $15 \mathrm{l} / \mathrm{s}$ per person are likely to increase the risk of the symptoms. The Finnish guideline value is $10 \mathrm{l} / \mathrm{s}$ per person.

The present study provides new evidence of an association between high ventilation rates and the risk of symptoms. This could indicate that mechanical ventilation systems may affect the indoor air quality by changing the physical property of air or by being a source of indoor air pollution. An alternative explanation is that high ventilation rates indicate a reaction to an existing indoor air problem. This observation should be interpreted with caution, because of the limitations of the study design.

This study was supported by the Ministry of Financial Affairs, Finland.

1 Finnegan MJ, Pickering CAC, Burge PS. Sick building syndrome: prevalence studies. BMF 1984;289:1573-5.

2 Jaakkola JJK. Indoor air in office building and human health. Experimental and epidemiologic study of the effects of mechanExperimental and epidemiologic study of the effects of mechanical ventilation. Helsinki: Department of Public Health, University of Helsinki, 1986. (Health Services Research by the National Board of Health in Finland, No 41. In
Finnish with an English summary. Doctoral thesis.)

Finnish with an English summary. Doctoral thesis.)
a Jaakkola JJK, Heinonen OP, Seppänen O. Mechanical Jaakkola JJK, Heinonen OP, Seppänen $O$. Mechanical
ventilation in office buildings and the sick building syndrome. An experimental and epidemiological study. Indoor Air 1991;1:111-21.

3 Skov P, Valbjørn O, and DISG. The "sick" building syndrome in the office environment: the Danish Town Hall study. Environ Int 1987;13:339-49.

4 Burge S, Hedge A, Wilson S, Harris-Bass J, Robertson A Sick building syndrome: a study of 4373 office workers Ann Occup Hyg 1987;31:493-504. 
5 Norbäck D, Rand G, Michel I, Amcoff S. The prevalence of symptoms associated with sick buildings and polluted industrial environments as compared to unexposed reference groups without expressed dissatisfaction. Environ Int 1989;15:85-94.

6 Zweers T, Preller L, Brunekreef B, Boleij JSM. Health and indoor climate complaints of 7043 office workers in 61 buildings in the Netherlands. Indoor Air 1992;2:127-36.

7 Fisk WJ, Mendell MJ, Daisey JM, Faulkner D, Hodgson AT, Nematollah M, Macher JM. Phase 1 of the California healthy building study: a summary. Indoor Air 1993;3:246-54.

8 Stenberg B, Mild KH, Sandström M, Sundell J, Wall S. A prevalence study of the sick building syndrome and facial skin symptoms in office workers. Indoor Air 1993;3: 71-81.

9 Indoor air pollutants: exposure and health effects. Report on a World Health Organisation meeting. Copenhagen, Denmark: World Health Organisation Regional Office for Europe, 1983. (EURO reports and studies No 78.)

10 Jaakkola JJK, Miettinen P. Type of ventilation system in office buildings and sick building syndrome. Am Epidemiol 1995:141:755-65.

11 Skov P, Valbjørn O, Pedersen BV. Influence of indoor climate on the sick building syndrome. Scand $f$ Work mate on the sick building sy

12 Hedge A, Burge PS, Robertson AS, Wilson S, Harris-Bass J. Work-related illness in offices: a proposed model of the "sick building syndrome". Environ Int 1989;15:143-58.

13 Mendell MJ, Smith AH. Consistent pattern of elevated symptoms in air-conditioned office buildings: a reanalysis of epidemiologic studies. Am $\mathcal{F}$ Public Health 1990;80 1193-9.
14 Sundell J, Lindvall T, Stenberg B. Associations between type of ventilation and air flow rates in office buildings and the risk of SBS-symptoms among occupants. Environ Int 1994;20:239-51.

15 Jaakkola JJK, Heinonen OP, Seppänen O. Mechanical ventilation in office buildings and the sick building syndrome. An experimental and epidemiological study. Indoor Air 1991;1:111-21.

16 Menzies R, Tamblyn R, Farant J-P, Hanley J, Nunes F, Tamblyn $R$. The effect of varying levels of outdoor-air supply on the symptoms of sick building syndrome. NEngl f Med 1993;328:821-7.

17 Wyon D. Sick buildings and the experimental approach Environmental Technology 1992;13:313-22.

18 Nagda NL, Koontz MD, Albrecht RJ. Effect of ventilation rate in a healthy building. In: Healthy buildings: Proceedings of the ASHRAE LAQ'91 Conference. Washington, DC: ASHRAE, 1991;101-7.

19 Jaakkola JK, Tuomaala P, Seppänen O. Air recirculation and sick building syndrome. A four period crossover trial. Am $\mathcal{F}$ Public Health 1994;84:422-8.

20 Stenberg B. Office illness. The worker, the work and the workplace. Umeå, Sweden; 1994. (Umeå University Medical Dissertaion). New Series No 399.

21 Mendell MJ. Non-specific symptoms in office workers: a review and summary of the epidemiologic literature. review and summary of

22 Miettinen OS. Theoretical epidemiology. Principles of occurrence research in medicine. New York: John Wiley, 1985.

23 Hosmer DW, Lemeshow S. Applied logistic regression. John Wiley, 1989.

24 Berglund B, Lindvall T. Sensory reactions to "sick buildings". Environ Int 1986;12:147-59.

\section{Instructions to authors}

Three copies of all submissions should be sent to: The Editor, Occupational and Environmental Medicine, BMJ Publishing Group, BMA House, Tavistock Square, London WC1H 9JR, UK. All authors should sign the covering letter as evidence of consent to publication. Papers reporting results of studies on human subjects must be accompanied by a statement that the subjects gave written, informed consent and by evidence of approval from the appropriate ethics committee. These papers should conform to the principles outlined in the Declaration of Helsinki (BMF 1964; ii:177).
If requested, authors shall produce the data on which the manuscript is based, for examination by the Editor.

Authors are asked to submit with their manuscript the names and addresses of three people who they consider would be suitable independent reviewers. They will not necessarily be approached to review the paper.

Papers should include a structured abstract of not more than 300 words, under headings of Objectives, Methods, Results, and Conclusions. Please include up to three keywords or key terms to assist with indexing. 